\title{
O campo das plantas medicinais no Brasil: lições de uma história
}

\author{
The field of medicinal plants \\ in Brazil: lessons from a history
}

\author{
Kenneth Rochel de Camargo Jr. \\ Instituto de Medicina Social (IMS) da Universidade do \\ Estado do Rio de Janeiro (UERJ \\ Rua Afonso Pena 141/402 \\ 20170-244 Rio de Janeiro - RJ \\ kenneth@uerj.br
}

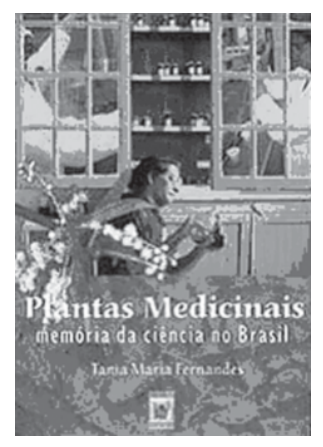

Fernandes, Tania Maria

Plantas medicinais: memória da ciência no Brasil.

Rio de Janeiro: Ed.

Fiocruz, 2004. 260 p.
Q ual a mola propulsora do desenvolvimento científico-tecnológico? Para os que baseiam seu pensamento na economia, a dinâmica econômica gera demandas que levam ao desenvolvimento de pesquisas e à produção de conhecimentos; para os que se baseiam nas próprias ciências, desenvolvimentos autônomos dos programas de pesquisa geram novos conhecimentos que se traduzem em inovações, e estas terminam percolando até as linhas de produção.

No caso específico estudado por Tania Fernandes, o desenvolvimento das pesquisas em plantas medicinais, ambas as escolas de pensamento poderiam com razão apontar elementos que dariam ganho de causa às suas respectivas abordagens; o curioso é que apesar da multiplicidade de interesses, o esperado encontro entre pesquisa e produção não se dá, em todo o longo período estudado pela autora, por razões que ela analisa em profundidade ao longo do seu texto.

Após uma breve porém densa reflexão teórica, verdadeiro tour de force acadêmico que passeia de Kuhn a Knorr-Cetina, passando por Bourdieu e Latour, a autora nos conduz pelo labirinto que mapeou, escudada em sólidas fontes históricas, tanto documentais quanto orais, baseando-se em entrevistas com os principais atores do campo.

Os vários saberes que poderiam constituir uma cadeia produtiva na área de fitoterápicos estão presentes: agrônomos, botânicos, farmacologistas e químicos, pesquisadores dos mais variados matizes, organizam-se a partir de encontros (Simpósios de Plantas Medicinais, 17 no período estudado) e estabelecem complexas relações com o Estado brasileiro, ainda durante o regime militar, mediadas pelos vários órgãos de fomento à pesquisa - $\mathrm{CNPq}$, Capes e Finep. Numa das muitas contradições que caracterizaram aquele regime, a área farmacêutica foi considerada prioritária para o projeto nacional, e estimulada através de mecanismos de indução tanto de pesquisas quanto da formação de núcleos de pós-graduação, ambas estratégias bem sucedidas no que diz respeito ao estabelecimento de uma área de pesquisas madura no país. Em paralelo, contudo, aprofundou-se o processo de desnacionalização da indústria farmacêutica no Brasil, o que se constituiu - e constitui - em efetiva barreira à transformação do conhecimento acumulado ao longo do período estudado em produtos efetivamente ao alcance da população. 
Curiosamente, anos após o fim do regime militar, compromissos outros dos governos civis que o sucederam mantêm e mesmo elevam as barreiras anteriormente constituídas, pela adesão a acordos de patentes contra os quais se insurgiram praticamente todos os pesquisadores do campo estudado. Acompanhando a trajetória estudada pela autora, vê-se que a abordagem governamental 'laissez faire' da indústria farmacêutica tornou-se efetivamente o maior obstáculo para o desenvolvimento do setor, impedindo a efetiva cooperação academiaindústria e possivelmente apartando a primeira de aportes de recursos que, sendo na configuração existente oriundos exclusivamente do Estado, tornam-se periodicamente rarefeitos.

Outro aspecto importante da pesquisa de Fernandes são as múltiplas facetas que ela apresenta, permitindo leituras variadas de sua narrativa. Do ponto de vista da história da ciência é interessante acompanhar as trajetórias pessoais e institucionais no período abordado, o que deixa claro a importância de fatores pessoais e contingentes no seu estabelecimento. Como exemplo, a extinção, em 1962, do Instituto de Química Agrícola, centro de excelência à época, mas que teve como efeito paradoxal a difusão mais ampla da pesquisa e do conhecimento que lá se produzia, tornando-se de certa forma o marco do começo efetivo desse campo no país.

Um olhar a partir da Saúde Coletiva, por sua vez, traz a primeiro plano a trajetória da Ceme - Central de Medicamentos, pensada originalmente como podendo ocupar a interface entre academia e indústria, mas que progressivamente esvaziada em suas funções tornou-se primordialmente uma repassadora de matéria-prima adquirida da indústria multinacional, criando um mercado consumidor que sem ela não existiria. Caracterizou, assim, mais um exemplo do tipo de política que Gentile de Melo rotulou de "socializar o prejuízo e privatizar o lucro". E o epílogo dessa instituição é particularmente doloroso: anos depois do término do regime militar, deveria ser supostamente seguido de redistribuição de suas funções a outros órgãos do Ministério da Saúde, o que não aconteceu. Não por acaso, sua desativação ocorre em 1997, dentro da mesma conjuntura que levou o Brasil a comprometer-se com uma legislação patentária visivelmente enviesada em direção aos interesses das corporações multinacionais, já apontada anteriormente nesta resenha.

Temos ainda as questões técnicas presentes no debate interno do próprio coletivo de pesquisadores: quanto à estratégia de identificação de plantas com potenciais interesses para a pesquisa, contrapondo os partidários de uma abordagem sistemática aos que favoreceriam a etnobotânica; ou ainda quanto à determinação de substâncias ativas, contrapondo farmacologistas preferindo trabalhar com componentes hidrossolúveis a químicos dando a precedência a substâncias solúveis em solventes orgânicos, exemplos modelares das controvérsias tão caras à sociologia da ciência.

Noutra chave, temos ainda a luta pela legitimação do próprio campo, visto como produtor de um "'remédio de pobre', de baixo custo e, portanto, de baixa qualidade", como enfatiza a autora, na página 224. É possível imaginar que outra frente de disputa nesse campo concen- 
tre-se nas práticas terapêuticas ditas 'alternativas' ou 'complementares', que a autora optou por não abordar, mas das quais os atores estudados claramente se diferenciam, sendo parte do mainstream da produção acadêmica biomédica. Quanto a este último aspecto, é digna de nota a baixa permeabilidade da prática médica aos medicamentos naturais, também apontada pela autora como obstáculo a ser superado. Mas aqui reside talvez outra questão importante para a pesquisa: para além das barreiras industriais, a baixa interação do campo pesquisado com médicos e/ou epidemiologistas pode também ter desempenhado um papel, além das barreiras industriais, na limitada aceitação, ainda hoje, desse tipo de medicamento. Mais do que mudanças na formação profissional do médico, corretamente apontadas pela autora, esta lacuna demandaria estratégias efetivas de incorporação desses quadros ao próprio campo tecnocientífico por ela estudado. Esta é na verdade uma questão estratégica em vários níveis, uma vez que a participação em 'pesquisas' patrocinadas pela indústria farmacêutica é uma de suas principais estratégias mercadológicas para estabelecer e manter sua dominância.

Em suma, ao retratar um exemplo específico e bem delimitado de estabelecimento de um campo técnico-científico no Brasil - e tornandose referência obrigatória sobre ele - Fernandes constrói uma obra cujo interesse se estende para muito além do campo que estudou, ou mesmo da própria história das ciências. Com tudo o que tem de específico e contingente, o estudo de caso que a autora nos apresenta oferece inúmeras lições para o estudo da ciência e tecnologia no nosso país em geral, incluindo-se aí subsídios para a ação governamental que se proponha efetivamente a reduzir nossa dependência da indústria farmacêutica multinacional. A importância estratégica deste último tópico deveria ser óbvia, mas ainda assim talvez convenha ser mais explícito, invocando o exemplo da política nacional de HIV/Aids. Esta vem sendo permanentemente ameaçada, apesar de seu sucesso, pelas práticas abusivas de marcação de preço, mas tem usado, com sucesso, a ameaça da quebra de patentes (sancionada pela Organização Mundial do Comércio) como limitador do poder dessa indústria multinacional.

Caso as pontes entre academia e indústria tivessem sido estabelecidas com o mesmo denodo, a situação hoje poderia ser outra, bem mais confortável para a academia, a indústria e a saúde brasileiras.

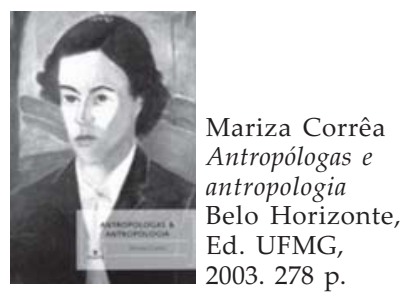

\section{ERRATA:}

Na última edição de História, Ciências, Saúde - Manguinhos (v. 12, n. 3) estampamos outra capa em lugar da que corresponderia ao livro de Mariza Corrêa, resenhado por Mariana Françozo, engano que corrigimos na presente edição, remetendo o leitor ao número anterior da revista (p. 1075-9) onde o texto da resenha foi publicado corretamente. 